\title{
Bovine embryo induces an anti-inflammatory response in uterine epithelial cells and immune cells in vitro: possible involvement of interferon tau as an intermediator
}

\author{
Anup K. TALUKDER ${ }^{1,2)}$, Mohamed S. YOUSEF 1, 3), Mohammad B. RASHID ${ }^{1,4)}$, \\ Kensuke AWAI ${ }^{5)}$, Tomas J. ACOSTA ${ }^{6}$, , Takashi SHIMIZU1), Kiyoshi OKUDA ${ }^{1,7)}$, \\ Masayuki SHIMADA ${ }^{8)}$, Kazuhiko IMAKAWA ${ }^{9)}$ and Akio MIYAMOTO ${ }^{1)}$ \\ 1) Graduate School of Animal and Food Hygiene, Obihiro University of Agriculture and Veterinary Medicine, \\ Hokkaido 080-8555, Japan \\ 2) Department of Gynecology, Obstetrics and Reproductive Health, Faculty of Veterinary Medicine and Animal Science, \\ Bangabandhu Sheikh Mujibur Rahman Agricultural University, Gazipur 1706, Bangladesh \\ 3) Department of Theriogenology, Faculty of Veterinary Medicine, Assiut University, Assiut, Egypt \\ 4) Department of Physiology and Pharmacology, Faculty of Veterinary and Animal Science, Hajee Mohammad Danesh \\ Science and Technology University, Dinajpur 5200, Bangladesh \\ 5) AG Embryo Support Co., Ltd., Hokkaido 080-0012, Japan \\ 6) Field Center of Animal Science and Agriculture, Obihiro University of Agriculture and Veterinary Medicine, \\ Hokkaido 080-8555, Japan \\ 7) Graduate School of Environmental and Life Science, Okayama University, Okayama 700-8530, Japan \\ ${ }^{8)}$ Graduate School of Biosphere Science, Hiroshima University, Hiroshima 739-8528, Japan \\ 9) Animal Resource Science Center, Graduate School of Agricultural and Life Sciences, The University of Tokyo, \\ Ibaraki 319-0206, Japan
}

\begin{abstract}
Recent observations suggest that the bovine uterus starts to react to the early embryo immediately after its arrival from the oviduct. The present study aimed to investigate the effect of the early developing embryo on the immune-related gene profile in bovine uterine epithelial cells (BUECs) in vitro, and to further examine the impact of conditioned media (CM), either from embryo-BUEC co-culture or embryo culture alone, on gene expression in peripheral blood mononuclear cells (PBMCs). First, BUECs were co-cultured with morulae $(\mathrm{n}=10)$ for D5-D9 (D0 = IVF), and gene expression in BUECs was analyzed. Subsequently, PBMCs were cultured in CM from embryo-BUEC co-culture or D5-D9 embryo culture, and gene expression was evaluated. In BUECs, the embryo induced interferon (IFN)-stimulated genes (ISGs: ISG15, OAS1, and $M X 2$ ), a key factor for IFN-signaling (STAT1), and type-1 IFN receptors (IFNAR1 and IFNAR2), with suppression of $N F k B 2, N F k B I A$ and pro-inflammatory cytokines (TNFA and IL1B). The embryo also stimulated PTGES and PGE2 secretion in BUECs. In PBMCs, both CM from embryo-BUEC co-culture and embryo culture alone induced ISGS, STAT1 and TGFB1, while suppressing TNFA and IL17. Similarly, interferon tau (IFNT) at $100 \mathrm{pg} / \mathrm{ml}$ suppressed $N F k B 2, T N F A$ and $I L 1 B$ in BUECs, and also stimulated TGFB1 and suppressed TNFA in PBMCs. Our findings suggest that the bovine embryo, in the first four days in the uterus (D5-D9), starts to induce an anti-inflammatory response in epithelial cells and in immune cells. IFNT is likely to act as one of the intermediators for induction of the anti-inflammatory response in the bovine uterus.
\end{abstract}

Key words: Bovine, Embryo, Interferon tau (IFNT), Immunity, Uterus

(J. Reprod. Dev. 63: 425-434, 2017)

$\mathbf{T}$ he female reproductive tract (FRT) is equipped with a unique and well-developed mucosal immune system that plays dual roles by accepting allogenic sperm and a semi-allogenic embryo/ fetus, while providing protection against pathogens [1, 2]. After

Received: April 19, 2017

Accepted: May 19, 2017

Published online in J-STAGE: June 10, 2017

(C)2017 by the Society for Reproduction and Development

Correspondence: A Miyamoto (e-mail: akiomiya@obihiro.ac.jp)

This is an open-access article distributed under the terms of the Creative Commons Attribution Non-Commercial No Derivatives (by-nc-nd) License. (CC-BY-NC-ND 4.0: https://creativecommons.org/licenses/by-nc-nd/4.0/) fertilization, the embryo stays in the bovine oviduct for about 4 days, and enters into the uterus at approximately the 16-cell or early morula stage [3, 4]. In the uterus, the embryo develops to blastocyst by D7, hatches from the zona pellucida between D9 and D10, and begins to elongate and form a filamentous conceptus that attaches to the uterine epithelium on D19 in cattle $[4,5]$. Several studies have investigated the immunological interaction between embryo and endometrium in cattle after hatching of the embryo (D12-13), during maternal recognition of pregnancy (D16), and during the peri-implantation period (D18-19) [6-10]. In contrast, there are few studies in cattle that focus on the uterine immune response to the pre-implantation embryo, particularly during the period from the 
arrival of the morula into the uterus (D5) until the hatching of the blastocyst (D9). It was observed that nuclear factor kappa B (NFkB) protein, a central mediator of inflammatory and immune responses, was down-regulated in bovine uterine fluid on D8 of pregnancy, which may confer tolerance to the semi-allogenic embryo in the uterus [11]. It should be noted that the bovine blastocyst expresses the paternal antigen of MHC molecule I on D7 of pregnancy [12, 13], and it therefore could be considered as foreign to the FRT. However, the blastocyst somehow escapes from maternal immune attack and establishes pregnancy in the uterus.

In ruminants, conceptus-derived interferon tau (IFNT) is a pregnancy recognition signal that indirectly inhibits PGF2 $\alpha$ release from the endometrial epithelium on D16, and thereby prevents the corpus luteum from regression and maintains pregnancy [14, 15]. Apart from its anti-luteolytic function, IFNT is considered as an immunosuppressive molecule that inhibits proliferation of lymphocytes, and thus may protect the semi-allogenic fetus from maternal immune attack [16]. Furthermore, the interferon-stimulated genes (ISGS) were activated in peripheral blood leukocytes during early pregnancy in cows [17, 18], suggesting that the resident immune cells in the FRT may also respond to IFNT. Until recently, there was little or no information on the involvement of IFNT in embryo-maternal communication before elongation of the embryo, which starts from D12-D13 in cattle. However, IFNT mRNA is expressed and its protein can be detected in the trophectoderm of non-hatched blastocysts on D7 [19, 20]. Therefore, it is possible that a small amount of IFNT from very early stage embryo could be involved in modulation of the local immune response in the bovine uterus.

To date, the molecular mechanism involved in the acceptance of the semi-allogenic embryo in the uterus is poorly understood in cattle. The present study aimed to investigate the effect of the early developing embryo on the immune-related gene profile in bovine uterine epithelial cells (BUECs) using an in vitro model, and to examine the impact of conditioned media (CM) either from embryo-BUEC co-culture or embryo culture alone on gene expression in immune cells. We further examined the direct effect of IFNT on both BUEC and immune cell gene expression.

\section{Materials and Methods}

\section{Ethics statement}

Animal experiments were conducted in accordance with the Guiding Principles for the Care and Use of Research Animals Promulgated by Obihiro University of Agriculture and Veterinary Medicine, Japan. The protocol was approved by the Committee on the Ethics of Animal Experiments of the Obihiro University of Agriculture and Veterinary Medicine (Permit number 25-101).

\section{Experimental model}

We used an in vitro model (Fig. 1) to investigate the communication of the embryo with uterine epithelial cells and immune cells. First, bovine uterine epithelial cells (BUECs) were co-cultured with IVM-IVF-derived morulae $(\mathrm{n}=10)$ for 4 days to mimic in vivo conditions, from the arrival of the embryo into the uterus (D5) until the hatching of the blastocyst (D9). BUEC culture without embryos served as the control. The gene expression in BUECs was compared in the presence and absence of the embryo. ELISA was performed to determine the PGE2 and IFNT concentration in the conditioned media (CM) of embryo-BUEC co-culture and BUEC culture alone (control). Subsequently, peripheral blood mononuclear cells (PBMCs) were cultured in CM from embryo-BUEC co-culture or BUEC culture alone (control), and gene expression in the PBMCs was evaluated. Next, morulae $(n=10)$ were cultured alone without BUECs for 4 days. At the same time, the fresh medium without embryos was incubated for 4 days. PBMCs were cultured in $\mathrm{CM}$ from embryo culture or in CM without embryos (control), and gene expression was analyzed in the PBMCs.

\section{Culture of BUECs}

The reproductive tracts of cows at luteal phase (D5-D7) were collected from a local slaughterhouse (Hokkaido Livestock, Doto Plant Tokachi Factory; Obihiro, Hokkaido, Japan) and transported to the laboratory in physiological saline containing $1 \%$ penicillinstreptomycin (Gibco, Grand Island, NY, USA) and 1\% amphotericin $\mathrm{B}$ (Gibco). The phase of the estrous cycle was identified as previously reported [21]. The uterine horn, ipsilateral to the corpus luteum, was used for isolation and culture of epithelial cells according to a previously described method [22], with minor modifications. Briefly, epithelial cells were cultured in DMEM/F12 (Gibco) supplemented with $2.2 \% \mathrm{NaHCO}_{3}$ (Sigma-Aldrich, Steinheim, Germany), 1\% penicillin-streptomycin, 1\% amphotericin B and 10\% FCS (Bio Whittaker, Walkersville, MD). The cells were seeded in $25 \mathrm{~cm}^{2}$ culture flasks (Nalge Nunc International, Roskilde, Denmark) and cultured at $38.5^{\circ} \mathrm{C}$ in a humidified atmosphere of $5 \% \mathrm{CO}_{2}$ in air. The medium was changed every $48 \mathrm{~h}$ until growing BUECs reached to $70-80 \%$ confluence, at which point cells were given a second passage. The cells were trypsinized ( $0.05 \%$ trypsin EDTA; Amresco, Solon, OH, USA), re-plated in 4- or 12-well plates (Nalge Nunc International) and cultured until sub-confluence. The BUECs from the second passage were supplemented with $5 \mathrm{ng} / \mathrm{ml}$ progesterone (P4) (Sigma-Aldrich) and $3 \mathrm{pg} / \mathrm{ml}$ estradiol 17ß (E2) (Sigma-Aldrich) as described previously [23]. The purity of the epithelial cells was evaluated by immunofluorescence staining using a monoclonal antibody against cytokeratin (anti-cytokeratin 8+18; ab53280, Abcam, Tokyo, Japan) as previously described [24]. The purity of the cultured uterine epithelial cells was $>98 \%$ (Fig. 2a and b).

\section{In vitro embryo production}

The in vitro maturation (IVM) and fertilization (IVF) were performed according to a previously described protocol [25] with minor modifications. Briefly, bovine cumulus oocyte complexes (COCs) were used for in vitro maturation for $22 \mathrm{~h}$, in a group of 30-40 in $500 \mu 1$ of high performance-modified 199 medium (HP-M199; Research Institute for the Functional Peptides, Yamagata, Japan) supplemented with $10 \mu \mathrm{g} / \mathrm{ml} \mathrm{FSH}$ (Follotropin-V, Bioniche Animal Health, Belleville, Ontario, Canada) and 5\% FCS in 4-well plates under mineral oil (Sigma-Aldrich) at $39^{\circ} \mathrm{C}$ in $5 \% \mathrm{CO}_{2}$ with humidified air. IVF was performed by co-incubation of 15 in vitro-matured COCs and sperm $\left(5 \times 10^{6} / \mathrm{ml}\right)$ in $50 \mu 1$ droplets of fertilization medium IVF100 (Research Institute for the Functional Peptides) under mineral oil for $6 \mathrm{~h}$ at $39^{\circ} \mathrm{C}$ in $5 \% \mathrm{CO}_{2}$ in humidified air. Subsequently, the presumptive zygotes $(\mathrm{n}=15)$ were transferred to $50 \mu$ d droplets of 
Embryo

Control

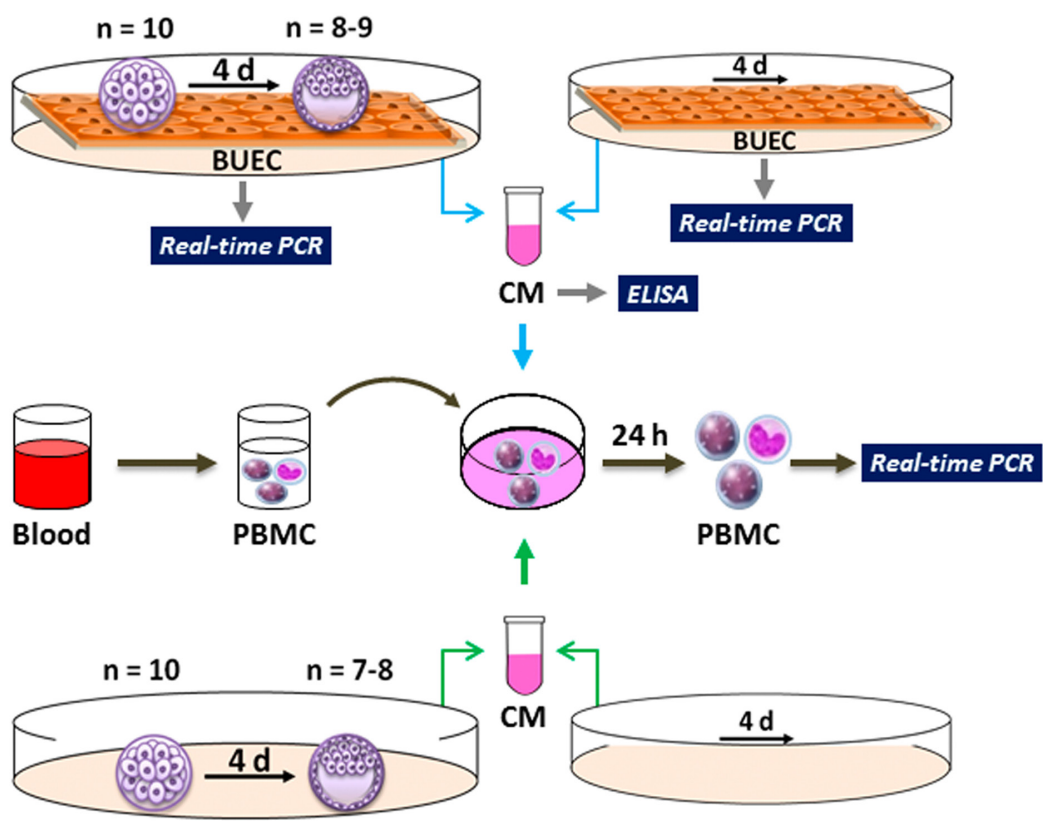

Fig. 1. Schematic representation of the experimental model. A BUEC monolayer was co-cultured with morulae $(n=10)$ or without (control) for 4 days. At the end of co-culture, morulae $(\mathrm{n}=8-9)$ were developed into blastocysts. Gene expression was analyzed in BUECs. Specific ELISAs for PGE2 and IFNT were used for determination of their concentration in the conditioned media $(\mathrm{CM})$. Then, PBMCs were cultured in CM from embryoBUEC co-culture or BUEC culture without embryo (control) for $24 \mathrm{~h}$, and the gene expression was evaluated in the PBMCs. Morulae $(\mathrm{n}=10)$ were cultured alone without BUECs for 4 days. At the end of culture, morulae $(n=7-8)$ had developed into blastocysts. Subsequently, PBMCs were cultured in $\mathrm{CM}$ from embryo culture or in CM without embryo (control) and gene expression was analyzed in the PBMCs.
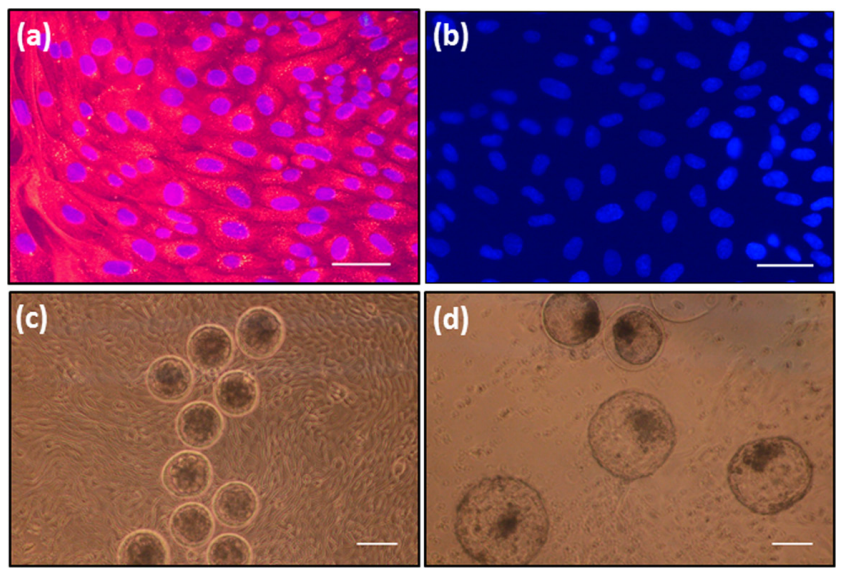

Fig. 2. (a) Immunofluorescence image of cultured BUECs with anticytokeratin antibody. Goat anti-rabbit IgG Alexa Flour 546 (red) was the secondary antibody, DAPI (blue) was used to visualize nuclei (b) Immunofluorescence image of cultured BUECs without anti-cytokeratin antibody as negative control. PBS-T $(0.1 \%$ Tween-20 in PBS- - ) was used instead of primary antibody (c) Morulae on the BUEC monolayer at the start of 4 day co-culture, and (d) Blastocysts on the BUEC monolayer at the end of 4 day co-culture. Scale bar $=100 \mu \mathrm{m}$ for $\mathrm{a}, \mathrm{b}$ and $200 \mu \mathrm{m}$ for c, $\mathrm{d}$.
KSOMaa (Zenith Biotech, Guilford CT, USA) supplemented with $5 \% \mathrm{FCS}$ under mineral oil at $38.5^{\circ} \mathrm{C}$ in a humidified atmosphere of $5 \% \mathrm{O}_{2}, 5 \% \mathrm{CO}_{2}$ and $90 \% \mathrm{~N}_{2}$ for in vitro culture (IVC). At $96 \mathrm{~h}$ of IVC (102 h after IVF), developing morulae were transferred onto a BUEC monolayer for co-culture.

For production of conditioned media (CM) from embryo culture without uterine epithelial cells (Fig. 1), IVC was first performed using 25-30 zygotes in $400 \mu \mathrm{K}$ KSOMaa medium supplemented with $5 \%$ FCS without mineral oil in 4 -well plates for 4 days. The developing morulae $(\mathrm{n}=10)$ were then transferred in $400 \mu \mathrm{l}$ fresh KSOMaa medium supplemented with $5 \%$ FCS for a further 4-day culture, at which point the medium was collected (denoted CM from embryo culture).

\section{Embryo-BUEC co-culture}

The BUEC culture medium was completely replaced with $400 \mu \mathrm{l}$ of KSOMaa with $5 \%$ FCS $6 \mathrm{~h}$ before adding the embryos. The morulae ( $\mathrm{n}=10$ per well), at $102 \mathrm{~h}$ after IVF, were transferred on a BUEC monolayer in 4-well plates, and incubated for 4 days at $38.5^{\circ} \mathrm{C}$ in a humidified atmosphere of $5 \% \mathrm{O}_{2}, 5 \% \mathrm{CO}_{2}$ and $90 \% \mathrm{~N}_{2}$. Half of the medium was replaced after $48 \mathrm{~h}$. At the end of co-culture, BUECs were lysed with Trizol, and stored at $-80^{\circ} \mathrm{C}$ until RNA extraction. Supernatants were stored at $-80^{\circ} \mathrm{C}$ for further use. The experiment was repeated six times and $80.0 \pm 2.6 \%(48 / 60)$ morulae developed 
into blastocysts, of which $35.0 \pm 2.2 \%$ were hatched at the end of the 4-day co-culture (Fig 2c and d).

\section{Isolation of PBMCs}

PBMCs were isolated as previously described [17] with minor modifications. Heparinized blood $(20 \mathrm{ml})$ from a multiparous Holstein cow during luteal phase was collected and mixed with an equal volume of PBS-/-, slowly layered over Ficoll-paque solution (Lymphoprep, Axis Shield, Oslo, Norway), and centrifuged at $1000 \times g$ for $35 \mathrm{~min}$ at $10^{\circ} \mathrm{C}$. The buffy coat (white layer containing mononuclear cells) was collected as PBMCs, mixed with hemolysis buffer $(155 \mathrm{mM}$ $\mathrm{NH}_{4} \mathrm{Cl}, 9.9 \mathrm{mM} \mathrm{KHCO}{ }_{3}, 96.7 \mu \mathrm{M}$ EDTA) for $10 \mathrm{sec}$, and centrifuged at $500 \times \mathrm{g}$ for $10 \mathrm{~min}$ at $10^{\circ} \mathrm{C}$ to remove red blood cells. After centrifugation, the cell pellet was washed twice with PBS-/-. The purity of PBMCs as evaluated by flow cytometry was $>98 \%$, and the viability as assessed by Trypan blue staining was around $99 \%$.

\section{Culture of PBMCs in conditioned media (CM) from embryo- BUEC co-culture}

PBMCs $\left(5 \times 10^{6}\right.$ cells) were cultured in a 48 -well plate (Nalge Nunc International) in $400 \mu \mathrm{l}$ CM from embryo-BUEC co-culture or in CM from BUEC culture without embryos (control) for $24 \mathrm{~h}$ in a humidified atmosphere at $38.5^{\circ} \mathrm{C}$ in $5 \% \mathrm{CO}_{2}$. After $24 \mathrm{~h}$ of incubation, the supernatant was removed and the cells were collected, lysed using Trizol, and then stored at $-80^{\circ} \mathrm{C}$ until RNA extraction.

\section{Culture of PBMCs in CM from embryo culture}

PBMCs $\left(5 \times 10^{6}\right.$ cells $)$ were cultured in a 48 -well plate in 400 $\mu 1 \mathrm{CM}$ from D5-D9 embryo culture or in CM without embryos (control) for $24 \mathrm{~h}$ in a humidified atmosphere at $38.5^{\circ} \mathrm{C}$ in $5 \% \mathrm{CO}_{2}$. After $24 \mathrm{~h}$ of incubation, the supernatant was removed and the cells were collected, lysed using Trizol, and then stored at $-80^{\circ} \mathrm{C}$ until RNA extraction.

\section{Treatment of BUECs and PBMCs with recombinant bovine IFNT (rbIFNT)}

The sub-confluent BUEC monolayers were washed twice and cultured in medium supplemented with $0.1 \%$ FCS in combination with $100 \mathrm{pg} / \mathrm{ml}$ of rbIFNT (bIFNT 2B, specific activity $=4.15 \times 10^{7}$ $\mathrm{U} / \mathrm{mg}$; Zenoaq, Koriyama, Japan) for $24 \mathrm{~h}$ in a humidified atmosphere at $38.5^{\circ} \mathrm{C}$ in $5 \% \mathrm{CO}_{2}$. BUECs without IFNT treatment served as the control. The dose of $100 \mathrm{pg} / \mathrm{ml}$ IFNT was chosen on the basis of preliminary experiments where a similar magnitude of ISG15 mRNA stimulation was observed in BUECs and PBMCs with this dose as with the embryo.

PBMCs $\left(5 \times 10^{6}\right.$ cells $)$ were also cultured in a 12 -well plate in $500 \mu 1$ RPMI-1640 medium (Sigma-Aldrich) supplemented with $0.1 \% \mathrm{FCS}$ in combination with $100 \mathrm{pg} / \mathrm{ml}$ of IFNT for $24 \mathrm{~h}$ in a humidified atmosphere at $38.5^{\circ} \mathrm{C}$ in $5 \% \mathrm{CO}_{2}$. PBMCs without IFNT treatment served as the control. At the end of culture of BUECs and PBMCs, the supernatant was removed and the cells were collected, lysed using Trizol, and then stored at $-80^{\circ} \mathrm{C}$ until RNA extraction.

\section{RNA extraction and $c D N A$ synthesis}

Total RNA was extracted from BUECs and PBMCs using the Trizol reagent as previously described [26]. The RNA extracted from all samples was detected by ultraviolet (UV) spectroscopy (optical density, $260 \mathrm{~nm}$ ) and the concentration was measured using a spectrophotometer (Eppendorf, Munich, Germany) at 260 and $280 \mathrm{~nm}$ absorbance values. The total extracted RNA was stored in RNA storage solution (Ambion, Austin, TX, USA) at $-80^{\circ} \mathrm{C}$ until cDNA conversion. The cDNA synthesis was carried out according to a previously described protocol [27]. The synthesized cDNA was stored at $-30^{\circ} \mathrm{C}$.

\section{Real-time PCR}

Quantitative real-time PCR of target genes (Table 1) was performed using QuantiTect SYBR Green PCR Master Mix (QIAGEN GmbH, Hilden, Germany) by an iCycler iQ (Bio-Rad Laboratories, Tokyo, Japan). The amplification program was set up according to a previously described protocol [27]. The calculated cycle threshold $(\mathrm{Ct})$ values were normalized using $B$-actin as the internal standard by applying the Delta-Delta comparative threshold method [28] to quantify the fold change between samples.

\section{ELISA for determination of PGE2 and IFNT concentration in conditioned media}

We used a commercially available ELISA kit for determination of PGE2 (R\&D systems, Minneapolis, MN, USA) and bovine specific IFNT (Cloud-Clone, Houston, TX, USA) concentration in conditioned media obtained from embryo-BUEC co-culture according to the manufacturers' instructions. The optical density (OD) value was detected using an ELISA microplate reader (Labsystem Multiskan MS 352, Labsystems, Finland) at $450 \mathrm{~nm}$ wavelength. Standard curves were prepared for PGE2 and IFNT in the range of 20-2500 $\mathrm{pg} / \mathrm{ml}$ and $7.8-500 \mathrm{pg} / \mathrm{ml}$, respectively.

\section{Statistical analysis}

Data are presented as mean \pm SEM. Statistical analysis was performed using SPSS software, version 14.0 (SPSS, Chicago, IL, USA). Student's t- test was applied to compare the data between two groups. P values $<0.05$ were considered to be statistically significant.

\section{Results}

The effect of embryos on gene expression and PGE2 secretion in BUECS

The developing embryos significantly $(\mathrm{P}<0.01)$ induced IFNstimulated genes (ISGs; ISG15,OAS1 and MX2) and a key factor for IFN-signaling (STAT1) with the stimulation of type-1 IFN receptors (IFNAR1 and IFNAR2) in BUECs. In addition, the embryos significantly suppressed $N F k B 2, N F k B I A$ and pro-inflammatory cytokines $(T N F A$ and $I L 1 B)(\mathrm{P}<0.01)$ in BUECs. There was no significant $(\mathrm{P}>0.05)$ change observed in the expression of anti-inflammatory cytokines (TGFBI and IL10) in BUECs in the presence of embryos. The developing embryos stimulated PTGES $(\mathrm{P}<0.01)$ in BUECs. In accordance with the gene expression data, the presence of the embryo increased the amount of PGE2 secretion from BUECs by 20 -fold when compared to that of the control $(\mathrm{P}<0.01)$ (Fig. 3). We could not determine the IFNT concentration in conditioned media from embryo-BUEC co-culture by ELISA. 
Table 1. Primers used in real-time PCR

\begin{tabular}{|c|c|c|c|}
\hline Gene & & Sequence of nucleotide $\left(5^{\prime} \rightarrow 3^{\prime}\right)$ & Accession no. \\
\hline \multirow[t]{2}{*}{ B-actin } & Forward & TCACCAACTGGGACGACATG & AY141970.1 \\
\hline & Reverse & CGTTGTAGAAGGTGTGGTGCC & \\
\hline \multirow[t]{2}{*}{$I S G 15$} & Forward & TCTGAGGGACTCCATGACGG & NM_174366 \\
\hline & Reverse & TTCTGGGCGATGAACTGCTT & \\
\hline \multirow[t]{2}{*}{ OAS1 } & Forward & TAGGCCTGGAACATCAGGTC & NM_178108 \\
\hline & Reverse & TTTGGTCTGGCTGGATTACC & \\
\hline \multirow[t]{2}{*}{$M X 2$} & Forward & CTTCAGAGACGCCTCAGTCG & NM_173941 \\
\hline & Reverse & TGAAGCAGCCAGGAATAGT & \\
\hline \multirow[t]{2}{*}{ STAT1 } & Forward & CTCATTAGTTCTGGCACCAGC & AW289395 \\
\hline & Reverse & CACACGAAGGTGATGAACATG & \\
\hline \multirow[t]{2}{*}{ IFNARI } & Forward & GCGAAGAGTTTCCGCAACAG & NM_174552.2 \\
\hline & Reverse & TCCAAGGCAGGTCCAATGAC & \\
\hline \multirow[t]{2}{*}{ IFNAR2 } & Forward & TCGTATGTTGCGCCTGTTCT & NM_174553.2 \\
\hline & Reverse & GTCCGTCGTGTTTACCCACA & \\
\hline \multirow[t]{2}{*}{ PTGES } & Forward & AAAATGTACGTGGTGGCCGT & NM_174443.2 \\
\hline & Reverse & CTTCTTCCGCAGCCTCACTT & \\
\hline \multirow[t]{2}{*}{$N F K B 2$} & Forward & CCTGCTGAATGCTCTGTCTG & NM_001102101.1 \\
\hline & Reverse & TCCTCCTTCACCTCTGTGCT & \\
\hline \multirow[t]{2}{*}{ NFKBIA } & Forward & AAGTGGTCCGCCAAGTGAAG & NM_001045868.1 \\
\hline & Reverse & CGATTTCTGGCTGGTTAGTGATC & \\
\hline \multirow[t]{2}{*}{ TNFA } & Forward & CAAAAGCATGATCCGGGATG & NM_173966.3 \\
\hline & Reverse & TTCTCGGAGAGCACCTCCTC & \\
\hline \multirow[t]{2}{*}{$I L 1 B$} & Forward & AATCGAAGAAAGGCCCGTCT & NM_174093.1 \\
\hline & Reverse & ATATCCTGGCCACCTCGAAA & \\
\hline \multirow[t]{2}{*}{$T G F B 1$} & Forward & СТTTCTTCAAATGCAGCATTGG & NM_001166068.1 \\
\hline & Reverse & GGGTCTGGGTGATACAACGAA & \\
\hline \multirow[t]{2}{*}{ IL10 } & Forward & GAGATGCGAGCACCCTGTCT & NM_174088.1 \\
\hline & Reverse & GGCTGGTTGGCAAGTGGATA & \\
\hline \multirow[t]{2}{*}{ IL17 } & Forward & CACAGCATGTGAGGGTCAAAC & NM_001008412 \\
\hline & Reverse & GGTGGAGCGCTTGTGATAAT & \\
\hline
\end{tabular}

The effect of CM from embryo-BUEC co-culture on gene expression in PBMCs

The CM from embryo-BUEC co-culture significantly induced ISGs and STAT1 $(\mathrm{P}<0.01)$ in PBMCs. CM from embryo-BUEC co-culture also stimulated TGFB1 $(\mathrm{P}<0.05)$, while suppressing TNFA and ILI7 $(\mathrm{P}<0.05)$ in PBMCs (Fig. 4).

The effect of CM from embryo culture on gene expression in PBMCs

The CM from embryo culture significantly induced ISGs, STATI, IFNAR 1 and IFNAR2 in PBMCs $(\mathrm{P}<0.01)$. CM from embryo culture also increased $P T G E S$ and TGFB1 $(\mathrm{P}<0.05)$, but suppressed TNFA and IL17 $(\mathrm{P}<0.01)$ in PBMCs (Fig. 5).

The effect of IFNT on gene expression in BUECs and PBMCs

In BUECs, IFNT at $100 \mathrm{pg} / \mathrm{ml}$ induced ISG15 and PTGES, while suppressing NFkB2, TNFA and $I L 1 B$, as well as stimulating TGFB1 $(\mathrm{P}<0.05)$ (Fig. 6a). On the other hand, in PBMCs, IFNT at $100 \mathrm{pg} /$ $\mathrm{ml}$ stimulated $I S G 15$, while down-regulating TNFA and up-regulating
TGFB1 and $I L 10(\mathrm{P}<0.05)$ (Fig. 6b).

\section{Discussion}

Successful pregnancy requires acceptance of a semi-allogenic embryo/fetus into the uterus by the maternal immune system, which is achieved by a series of complex interactions between the embryo and the maternal tract. In the present study, we used a simplified co-culture model to provide in vitro evidence that the uterine epithelial cells can recognize the IFNT signal from the bovine early embryo from morula (D5) to blastocyst (D9) stage, and generate an antiinflammatory response to the embryo. Moreover, this study shows the first in vitro evidence that the early embryo can modulate gene expression of immune cells (PBMCs) towards suppression during this period of development, which might occur very early during pregnancy in cows, for the acceptance of a semi-allogenic embryo into the uterus.

In the present study, the developing embryos induced ISGs, STATI and type-1 IFN receptors (IFNARI and IFNAR2) in BUECs. Our 


\section{BUEC}

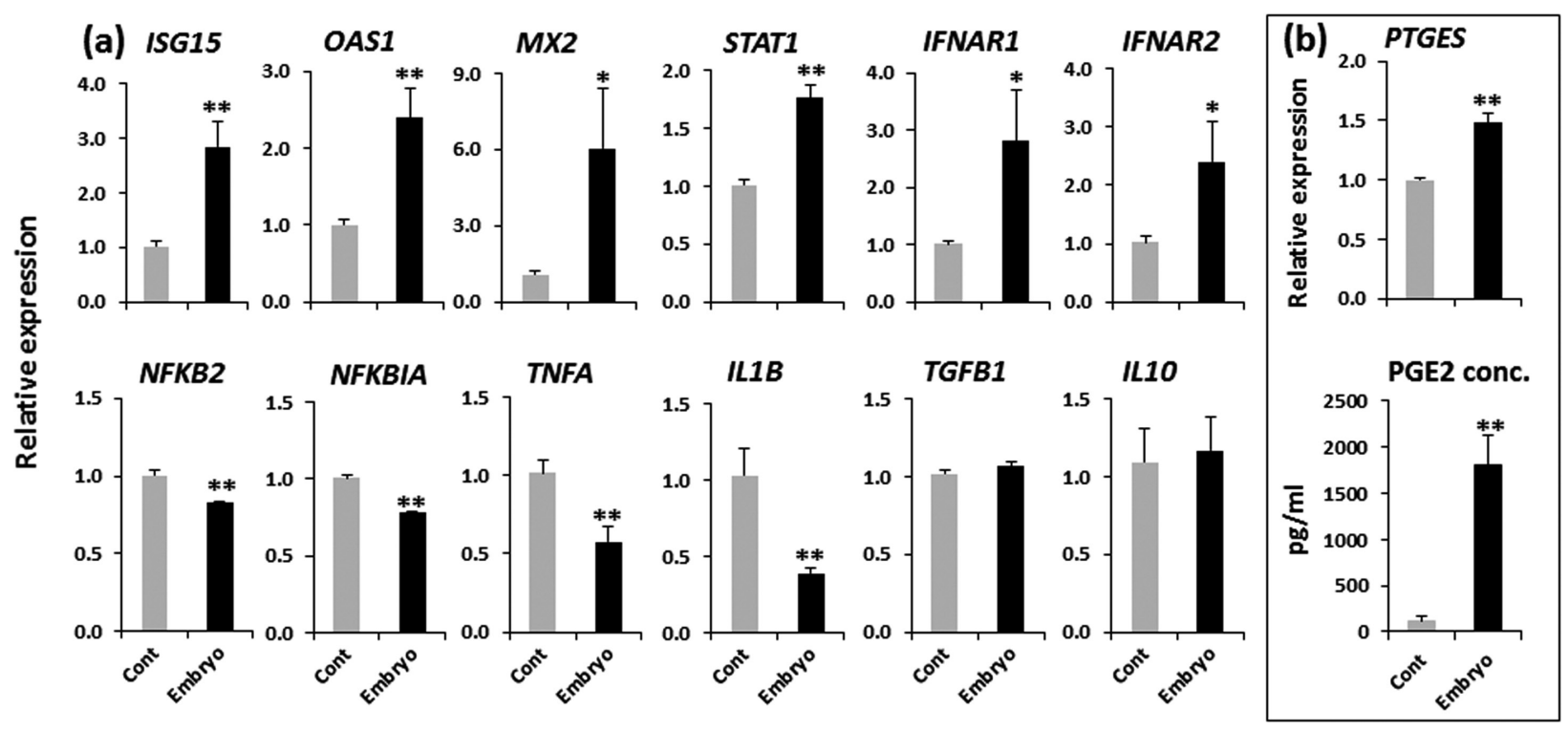

Fig. 3. The effect of developing embryos on gene expression and PGE2 secretion in BUECs. (a) Relative mRNA expression of IFN-stimulated genes (ISG15, OAS1 and MX2), a key factor for IFN-signaling (STAT1), type-1 IFN receptors (IFNAR1 and IFNAR2), key factors for the inflammatory response (NFKB2 and NFKBIA), pro-inflammatory cytokines (TNFA and IL1B) and anti-inflammatory cytokines (TGFB1 and IL10), and (b) Relative mRNA expression of an enzyme involved in prostaglandin E synthesis (PTGES) and secretion of PGE2 from BUECs after co-culture with the embryo. Data are presented as mean \pm SEM of six experiments. Asterisks denote a statistically significant difference: $* \mathrm{P}<0.05$, ** $\mathrm{P}<$ 0.01 , when compared to the control.

\section{PBMC}

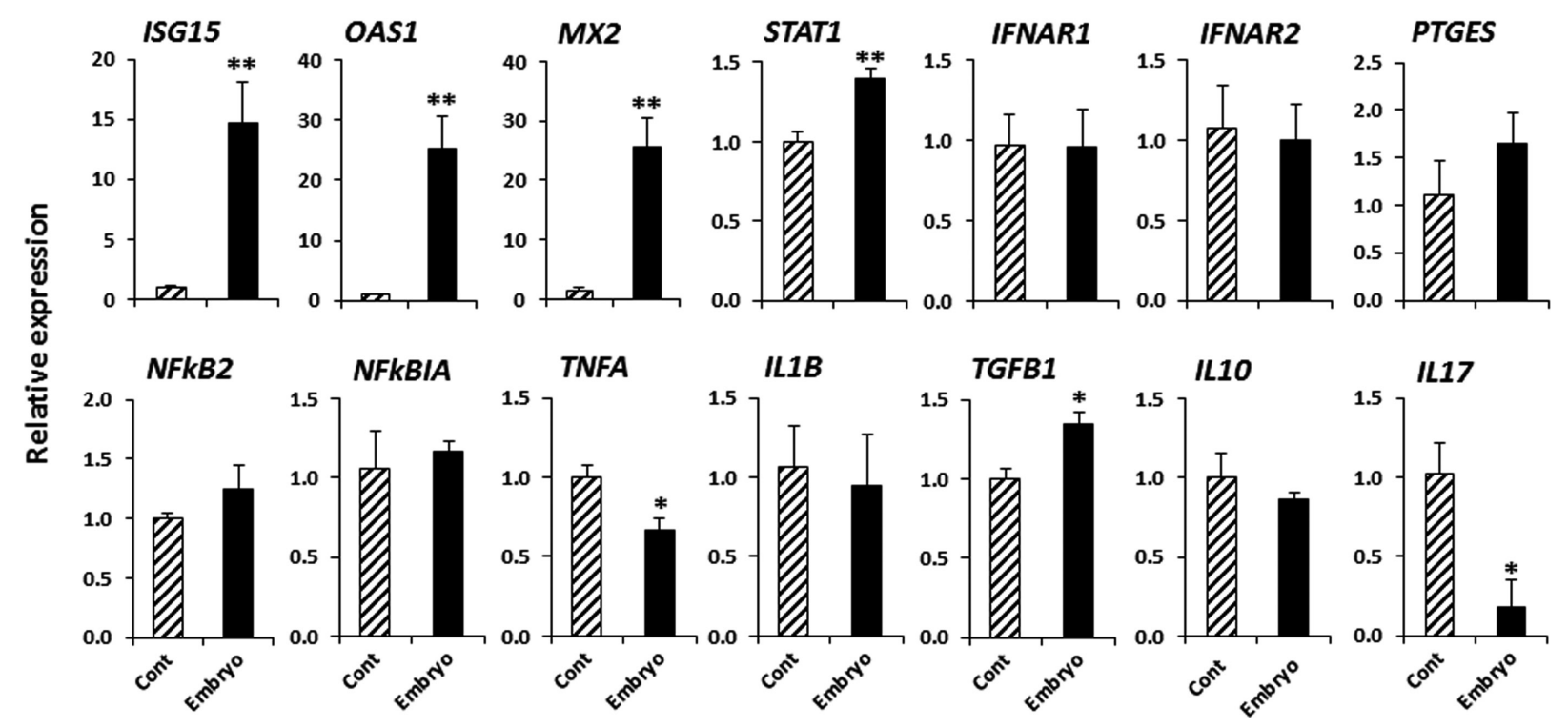

Fig. 4. The effect of conditioned media from embryo-BUEC co-culture on gene expression in PBMCs. CM from BUEC culture without embryos served as the control. Relative mRNA expression of IFN-stimulated genes (ISG15, OAS1 and MX2), a key factor for IFN-signaling (STAT1), type-1 IFN receptors (IFNARI and IFNAR2), an enzyme involved in prostaglandin E synthesis (PTGES), key factors for the inflammatory response (NFKB2 and NFKBIA), Th1 cytokines (TNFA and IL1B), Th2 cytokines (TGFB1 and IL10) and Th17 cytokine (IL17). Data are presented as mean \pm SEM of six experiments. Asterisks denote a statistically significant difference: $* \mathrm{P}<0.05,{ }^{*} \mathrm{P}<0.01$, when compared to the control. 
PBMC

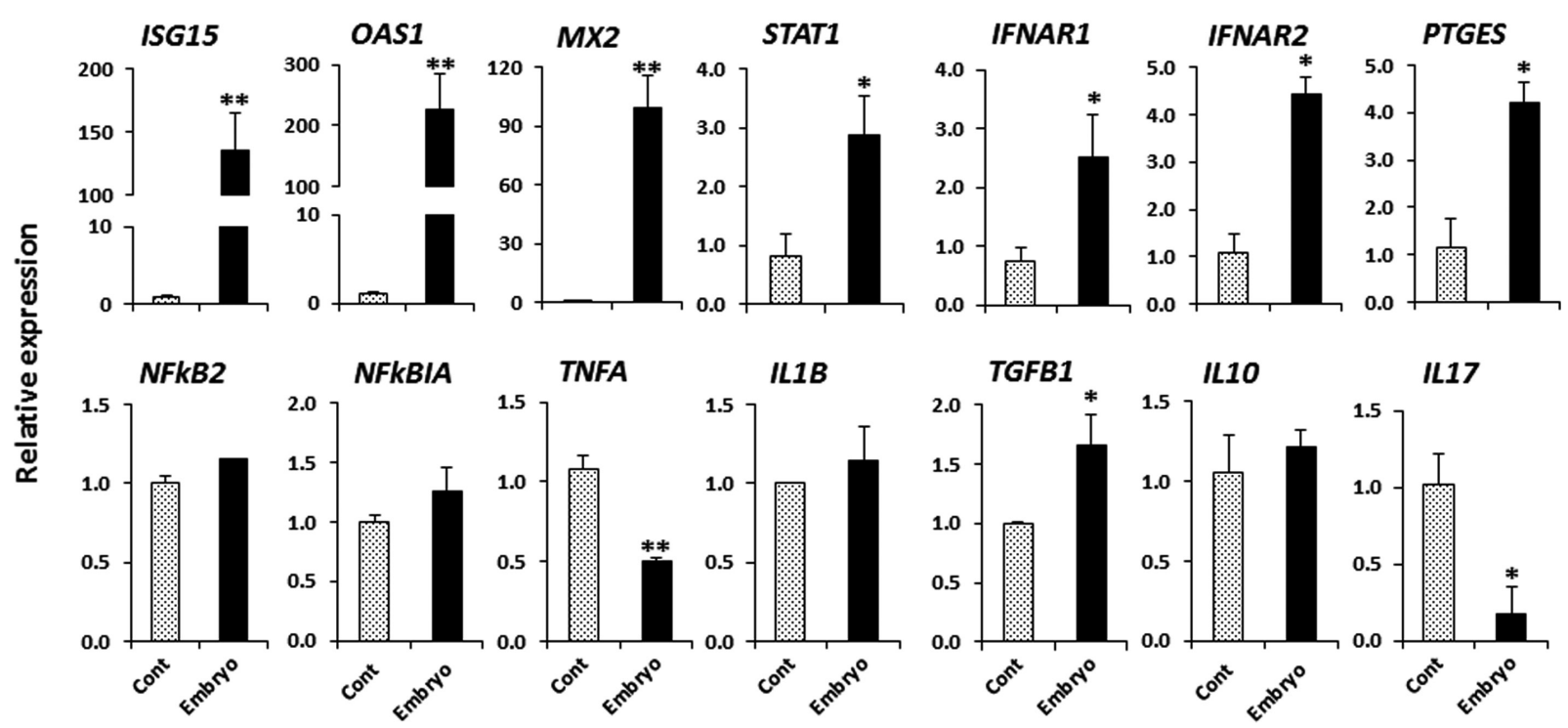

Fig. 5. The effect of conditioned media from D5-D9 embryo culture on gene expression in PBMCs. CM without embryos served as the control. Relative mRNA expression of IFN-stimulated genes (ISG15, OAS1 and MX2), a key factor for IFN-signaling (STAT1), type-1 IFN receptors (IFNARI and IFNAR2), an enzyme involved in prostaglandin E synthesis (PTGES), key factors for the inflammatory response (NFKB2 and NFKBIA), Th1 cytokines (TNFA and IL1B), Th2 cytokines (TGFB1 and IL10) and Th17 cytokine (IL17). Data are presented as mean \pm SEM of three experiments. Asterisks denote a statistically significant difference: $* \mathrm{P}<0.05, * * \mathrm{P}<0.01$, when compared to the control.

\section{(a) BUEC}

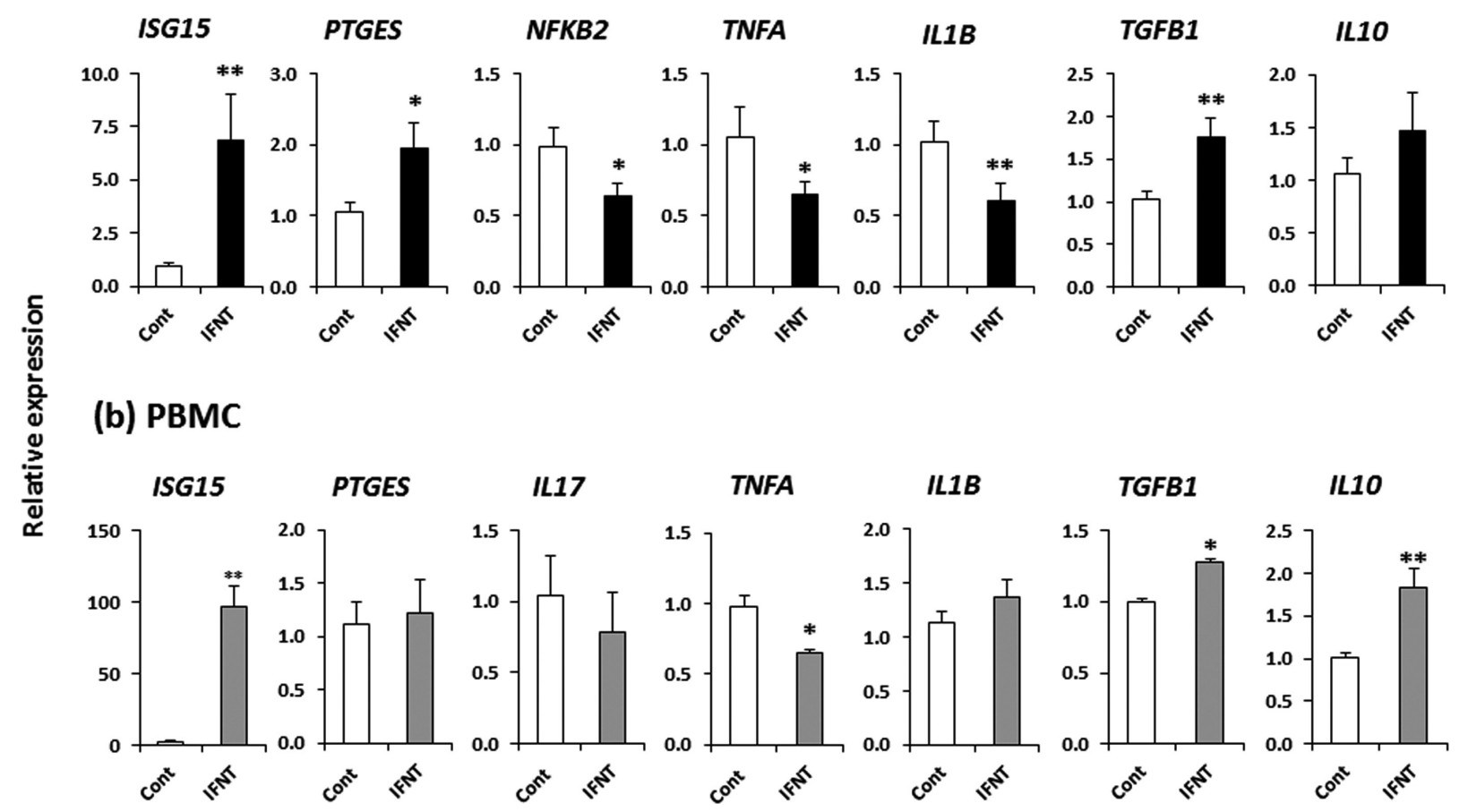

Fig. 6. The effect of IFNT $(100 \mathrm{pg} / \mathrm{ml})$ on gene expression in BUECs and PBMCs. (a) Relative mRNA expressions of ISG15, PTGES, NFkB2, proinflammatory cytokines (TNFA and $I L 1 B)$ and anti-inflammatory cytokines (TGFBI and IL10) in BUECs, and (b) Relative mRNA expressions of ISG15, PTGES, Th17 cytokine (IL17), Th1 cytokines (TNFA and IL1B) and Th2 cytokines (TGFB1 and IL10) in PBMCs. Data are presented as mean \pm SEM of three experiments. Asterisks denote a statistically significant difference: $* \mathrm{P}<0.05, * * \mathrm{P}<0.01$, when compared to the control. 
findings suggest that the morula (D5) to blastocyst stage (D9) embryo secretes significant amount of IFNT that can eventually activate interferon-signaling cascades in BUECs. In contrast with our findings with D5-D9 embryos, it has been observed that the embryo induces $I S G s$ expression in the bovine endometrium as early as D13 of pregnancy in cattle [7]. Failure to detect ISGs expression in the endometrium before elongation of the embryo (D5 or D7 of pregnancy) in cattle could be due to the small-size of the embryo, which might elicit a very local effect on the endometrium, and may not be detected by transcriptome analysis of a large endometrial sample. In the present study, we applied 10 embryos onto the BUEC monolayer, which might have amplified the embryo-derived IFNT signal and thus the ISGs expression in BUECs. Our results suggest that "very early" maternal recognition of pregnancy could occur around D8 of pregnancy in cattle. In fact, we could not determine IFNT concentration in the conditioned media from embryo-BUEC co-culture. This may be because we used 5\% FCS in the media for embryo-BUEC co-culture, which appears to disrupt the sensitivity and specificity of the ELISA. It should be noted that biological activity of IFNT was detected in embryo-conditioned medium, where in vivo derived blastocysts at D8.5-9.5 were cultured for 24-48 h [29], and this strongly supports our finding.

PTGES expression and PGE2 secretion were stimulated in BUECs by early developing embryos. Our result is in agreement with other studies, which have reported up-regulation of PTGES expression in the uterus in the presence of a viable embryo on D6-7 of pregnancy in cattle $[30,31]$. It has also been reported that PGE2 is secreted from both conceptus and maternal endometrium at the feto-maternal interface throughout the pregnancy, which may be an important immunomodulatory agent to protect the semi-allogenic fetus from maternal immunological attack in cows and ewes [32]. The exact mechanism by which the embryo stimulates PGE2 secretion from BUECs is not known; however, there is evidence that IFNT could stimulate PGE2 secretion in the bovine endometrium [33]. Thus, in the present study, embryo-derived IFNT might contribute to stimulation of PGE2 secretion from BUECs.

The developing embryos suppressed $N F k B 2$ and $N F k B I A$ expression in BUECs, accompanied by decreased expression of pro-inflammatory cytokines (TNFA and $I L 1 B$ ). A very recent study demonstrated that IFNT plays an anti-inflammatory role in endometritis in mice, through suppression of the NFkB pathway and inhibition of TNFA and IL1B production [34]. Therefore, the reduction in expression of pro-inflammatory cytokines in BUECs is likely to be as a result of down-regulation of the $\mathrm{NFkB} / \mathrm{IkBa}$ signaling pathway $[35,36]$, mediated by embryo-derived IFNT.

Likewise in BUECs, the CM from embryo-BUEC co-culture induced ISGs and STATI in PBMCs. This finding suggests that IFNT is present in the conditioned media of embryo-BUEC co-culture, although we could not determine the IFNT concentration by ELISA. Successful pregnancy has long been reported to be a Th2 phenomenon [37], while Th1 dominance is observed in pregnancy failure [38]. The Th1/Th2 paradigm has recently extended into a new Th1/Th2/ Th17/ regulatory T (Treg) paradigm. In the present study, the presence of the embryo stimulated PGE2 secretion from BUECs, and the CM from embryo-BUEC co-culture and embryo culture alone both significantly increased the expression of $T G F B 1$ in PBMCs. It is well known that TGF $\beta$ synergistically works with PGE2 to induce the differentiation of naïve $\mathrm{T}$ cells $(\mathrm{Th} 0)$ to regulatory $\mathrm{T}$ cells for immune suppression and tolerance [39]. On the other hand, TGF $\beta$ also enhances the differentiation of Th0 to Th17 cells, which express IL17, in the presence of pro-inflammatory cytokines such as IL1 or IL6 [40, 41]. In the present study, the expression of IL17 and TNFA was significantly suppressed in PBMCs by both CM from embryoBUEC co-culture and embryo culture alone. Therefore, the embryo induced TGFB1 in PBMCs and PGE2 secretion from BUECs may synergistically play a role in the induction of anti-inflammatory and immune tolerance conditions in the bovine uterus.

In comparison with conditioned media from embryo-BUEC co-culture, the $\mathrm{CM}$ from embryo culture alone induced a relatively higher expression of ISGS, with stimulation of IFNARI and IFNAR2 expression in PBMCs. These findings suggest that the CM from embryo culture alone contains a higher amount of IFNT than that of embryo-BUEC co-culture. There is a possibility that a low amount of IFNT is present in CM from embryo-BUEC co-culture, due to binding of IFNT to type-1 IFN receptors of the uterine epithelial cells. Moreover, we cannot exclude the possibility that BUECs might act on the embryo to decrease IFNT secretion in the co-culture model used in the present study, both of which requires further investigation.

In the present study, we stimulated BUECs with different concentrations of IFNT (10, 100 and $1000 \mathrm{pg} / \mathrm{ml}$, data not shown) for $24 \mathrm{~h}$, and found that IFNT at $100 \mathrm{pg} / \mathrm{ml}$ induced a similar trend in gene expression (e.g. stimulated PTGES, but suppressed NFkB2, TNFA, and $I L 1 B$ ) in BUECs as the D5-D9 embryo. However, unlike the embryo, IFNT also stimulated TGFB1 in BUECs. In PBMCs, IFNT at $100 \mathrm{pg} / \mathrm{ml}$ induced a similar response as the embryo, with TNFA suppression and TGFB1 up-regulation observed. However, IFNT did not suppress $I L 17$ but stimulated IL10 in PBMCs, unlike the embryo. All together, these results indicate that the gene expression response to IFNT in BUECs and PBMCs followed a similar trend to those observed with the embryo, suggesting that IFNT may be one of the intermediators from the embryo to BUECs and immune cells. Clearly, further investigation such as neutralization of IFNT or detection of IFNT using a sensitive ELISA, is required to clarify the role of IFNT on gene expression in PBMCs. Importantly, our findings are in agreement with others who demonstrated that early pregnancy favors an anti-inflammatory (Th2) response in the bovine endometrium on D13-16 of pregnancy [9], while the embryo is also known to induce expression of ISGS in the endometrium in pregnant cows [7]. In addition, other factors derived from the embryo may also play important roles in the immunological interaction observed in this study. It was proposed in human and mice that the early preimplantation embryo produces certain embryo- and species-specific soluble factor(s) which are recognized by resident immune cells in the FRT, and cause the maternal immune system to undergo functional changes during the very early stages of pregnancy [42, 43].

Taken together, our findings support the hypothesis that the developing embryo, in the first four days in the uterus (D5-D9), starts to secrete IFNT and induces an anti-inflammatory response in epithelial cells, with activation of ISGs. In addition, during this period the early embryo regulates the gene expression of immune cells towards anti-inflammatory action. A small amount of IFNT from the very early stage embryo is likely to be involved in modulation of 
this "local" immune response in the bovine uterus. Further study is needed to understand the molecular mechanisms involved in crosstalk between the embryo and the immune cells in the uterus during very early stages of pregnancy in cattle.

\section{Note added in proof}

After submission of this article, a paper was published by the Mario Binelli group (Sponchiado et al., 2017; PLoS One 12 (4): e0175954) describing that the IFN-signaling was detectable only in the utero-tubal junction (UTJ) and anterior region of uterine horn ipsilateral to the CL in cattle, where a D7 embryo was found. This in vivo investigation strongly supports our hypothesis that early developing embryo, in the first four days in the uterus (D5-D9), communicates "locally" with the uterine epithelial cells in cattle.

\section{Acknowledgements}

The authors thank Prof. Dr. Motoki Sasaki, Basic Veterinary Science, Obihiro University of Agriculture and Medicine, Japan for his technical help in staining of epithelial cells for cytokeratin. This work was supported by Grant-in Aid for Scientific Research (16H05013) of Japan Society for the Promotion of Science (JSPS).

\section{References}

1. Wira CR, Fahey JV, Sentman CL, Pioli PA, Shen L. Innate and adaptive immunity in female genital tract: cellular responses and interactions. Immunol Rev 2005; 206: 306-335. [Medline] [CrossRef]

2. Horne AW, Stock SJ, King AE. Innate immunity and disorders of the female reproductive tract. Reproduction 2008; 135: 739-749. [Medline] [CrossRef]

3. Hackett AJ, Durnford R, Mapletoft RJ, Marcus GJ. Location and status of embryos in the gential tract of superovulated cows 4 to 6 days after insemination. Theriogenology 1993; 40: 1147-1153. [CrossRef]

4. Spencer TE, Forde N, Dorniak P, Hansen TR, Romero JJ, Lonergan P. Conceptusderived prostaglandins regulate gene expression in the endometrium prior to pregnancy recognition in ruminants. Reproduction 2013; 146: 377-387. [Medline] [CrossRef]

5. Lonergan P. New insights into the function of progesterone in early pregnancy. Anim Front 2015; 5: 12-17. [CrossRef]

6. Walker CG, Meier S, Littlejohn MD, Lehnert K, Roche JR, Mitchell MD. Modulation of the maternal immune system by the pre-implantation embryo. BMC Genomics 2010; 11: 474. [Medline] [CrossRef]

7. Forde N, Carter F, Spencer TE, Bazer FW, Sandra O, Mansouri-Attia N, Okumu LA, McGettigan PA, Mehta JP, McBride R, OGaora P, Roche JF, Lonergan P. Conceptus-induced changes in the endometrial transcriptome: how soon does the cow know she is pregnant? Biol Reprod 2011; 85: 144-156. [Medline] [CrossRef]

8. Mansouri-Attia N, Oliveira LJ, Forde N, Fahey AG, Browne JA, Roche JF, Sandra O, Reinaud P, Lonergan P, Fair T. Pivotal role for monocytes/macrophages and dendritic cells in maternal immune response to the developing embryo in cattle. Biol Reprod 2012; 87: 123. [Medline] [CrossRef]

9. Oliveira LJ, Mansouri-Attia N, Fahey AG, Browne J, Forde N, Roche JF, Lonergan P, Fair T. Characterization of the Th profile of the bovine endometrium during the oestrous cycle and early pregnancy. PLoS ONE 2013; 8: e75571. [Medline] [CrossRef]

10. Kamat MM, Vasudevan S, Maalouf SA, Townson DH, Pate JL, Ott TL. Changes in myeloid lineage cells in the uterus and peripheral blood of dairy heifers during early pregnancy. Biol Reprod 2016; 95: 68. [Medline] [CrossRef]

11. Muñoz M, Corrales FJ, Caamaño JN, Díez C, Trigal B, Mora MI, Martín D, Carrocera S, Gómez E. Proteome of the early embryo-maternal dialogue in the cattle uterus. J Proteome Res 2012; 11: 751-766. [Medline] [CrossRef]

12. Templeton JW, Tipton RC, Garber T, Bondioli K, Kraemer DC. Expression and genetic segregation of parental BoLA serotypes in bovine embryos. Anim Genet 1987; 18: 317-322. [Medline] [CrossRef]

13. Low BG, Hansen PJ, Drost M, Gogolin-Ewens KJ. Expression of major histocompatibility complex antigens on the bovine placenta. $J$ Reprod Fertil 1990; 90: 235-243.
[Medline] [CrossRef]

14. Imakawa K, Anthony RV, Kazemi M, Marotti KR, Polites HG, Roberts RM. Interferon-like sequence of ovine trophoblast protein secreted by embryonic trophectoderm. Nature 1987; 330: 377-379. [Medline] [CrossRef]

15. Bazer FW, Spencer TE, Ott TL. Interferon tau: a novel pregnancy recognition signal Am J Reprod Immunol 1997; 37: 412-420. [Medline] [CrossRef]

16. Skopets B, Li J, Thatcher WW, Roberts RM, Hansen PJ. Inhibition of lymphocyte proliferation by bovine trophoblast protein-1 (type I trophoblast interferon) and bovine interferon-alpha I1. Vet Immunol Immunopathol 1992; 34: 81-96. [Medline] [CrossRef]

17. Shirasuna K, Matsumoto H, Kobayashi E, Nitta A, Haneda S, Matsui M, Kawashima C, Kida K, Shimizu T, Miyamoto A. Upregulation of interferon-stimulated genes and interleukin-10 in peripheral blood immune cells during early pregnancy in dairy cows. $J$ Reprod Dev 2012; 58: 84-90. [Medline] [CrossRef]

18. Pugliesi G, Miagawa BT, Paiva YN, França MR, Silva LA, Binelli M. Conceptus-induced changes in the gene expression of blood immune cells and the ultrasound-accessed luteal function in beef cattle: how early can we detect pregnancy? Biol Reprod 2014; 91: 95. [Medline] [CrossRef]

19. Lonergan P, Rizos D, Gutierrez-Adán A, Moreira PM, Pintado B, de la Fuente J, Boland MP. Temporal divergence in the pattern of messenger RNA expression in bovine embryos cultured from the zygote to blastocyst stage in vitro or in vivo. Biol Reprod 2003; 69: 1424-1431. [Medline] [CrossRef]

20. Johnson KM, Alvarez X, Borkhsenious ON, Kubisch HM. Nuclear and cytoplasmic localization of interferon- $\tau$ in in vitro-produced bovine blastocysts. Reprod Nutr Dev 2006; 46: 97-104. [Medline] [CrossRef]

21. Wijayagunawardane MP, Miyamoto A, Cerbito WA, Acosta TJ, Takagi M, Sato K. Local distributions of oviductal estradiol, progesterone, prostaglandins, oxytocin and endothelin-1 in the cyclic cow. Theriogenology 1998; 49: 607-618. [Medline] [CrossRef]

22. Skarzynski DJ, Miyamoto Y, Okuda K. Production of prostaglandin f(2alpha) by cultured bovine endometrial cells in response to tumor necrosis factor alpha: cell type specificity and intracellular mechanisms. Biol Reprod 2000; 62: 1116-1120. [Medline] [CrossRef]

23. Turner ML, Cronin JG, Healey GD, Sheldon IM. Epithelial and stromal cells of bovine endometrium have roles in innate immunity and initiate inflammatory responses to bacterial lipopeptides in vitro via Toll-like receptors TLR2, TLR1, and TLR6. Endocrinology 2014; 155: 1453-1465. [Medline] [CrossRef]

24. Kobayashi Y, Wakamiya K, Kohka M, Yamamoto Y, Okuda K. Summer heat stress affects prostaglandin synthesis in the bovine oviduct. Reproduction 2013; 146: 103-110. [Medline] [CrossRef]

25. Ideta A, Aoyagi Y, Tsuchiya K, Kamijima T, Nishimiya Y, Tsuda S. A simple medium enables bovine embryos to be held for seven days at $4^{\circ} \mathrm{C}$. Sci Rep 2013; 3: 1173. [Medline] [CrossRef]

26. Chomezynski P, Sacchi N. Single-step method of RNA isolation by acid guanidinium thiocyanate-phenol-chloroform extraction. Anal Biochem 1987; 162: 156-159. [Medline] [CrossRef]

27. Yousef MS, Marey MA, Hambruch N, Hayakawa H, Shimizu T, Hussien HA, Abdel-Razek AK, Pfarrer C, Miyamoto A. Sperm binding to oviduct epithelial cells enhances TGFB1 and IL10 expressions in epithelial cells as well as neutrophils in vitro: prostaglandin $\mathrm{E} 2$ as a main regulator of anti-Inflammatory response in the bovine oviduct. PLoS ONE 2016; 11: e0162309. [Medline] [CrossRef]

28. Livak KJ, Schmittgen TD. Analysis of relative gene expression data using real-time quantitative PCR and the 2(- $\Delta \Delta C(T))$ Method. Methods 2001; 25: 402-408. [Medline] [CrossRef]

29. Kimura K, Spate LD, Green MP, Murphy CN, Seidel GE Jr, Roberts RM. Sexual dimorphism in interferon-tau production by in vivo-derived bovine embryos. Mol Reprod Dev 2004; 67: 193-199. [Medline] [CrossRef]

30. Beltman ME, Forde N, Furney P, Carter F, Roche JF, Lonergan P, Crowe MA Characterisation of endometrial gene expression and metabolic parameters in beef heifers yielding viable or non-viable embryos on Day 7 after insemination. Reprod Fertil Dev 2010; 22: 987-999. [Medline] [CrossRef]

31. Binelli M, Scolari SC, Pugliesi G, Van Hoeck V, Gonella-Diaza AM, Andrade SCS, Gasparin GR, Coutinho LL. The transcriptome signature of the receptive bovine uterus determined at early gestation. PLoS ONE 2015; 10: e0122874. [Medline] [CrossRef]

32. Low BG, Hansen PJ. Actions of steroids and prostaglandins secreted by the placenta and uterus of the cow and ewe on lymphocyte proliferation in vitro. Am J Reprod Immunol Microbiol 1988; 18: 71-75. [Medline] [CrossRef]

33. Xiao CW, Liu JM, Sirois J, Goff AK. Regulation of cyclooxygenase-2 and prostaglandin F synthase gene expression by steroid hormones and interferon-tau in bovine endometrial cells. Endocrinology 1998; 139: 2293-2299. [Medline] [CrossRef]

34. Jiang K, Chen X, Zhao G, Wu H, Mi J, Qiu C, Peng X, Deng G. IFN- $\tau$ plays an antiinflammatory role in Staphylococcus aureus-induced endometritis in mice through the suppression of NF-kB pathway and MMP9 expression. J Interferon Cytokine Res 2017; 37: 81-89. [Medline] [CrossRef] 
35. McCracken SA, Gallery E, Morris JM. Pregnancy-specific down-regulation of NFkappa B expression in T cells in humans is essential for the maintenance of the cytokine profile required for pregnancy success. J Immunol 2004; 172: 4583-4591. [Medline] [CrossRef]

36. McCracken SA, Hadfield K, Rahimi Z, Gallery ED, Morris JM. NF-kappaB-regulated suppression of T-bet in T cells represses Th1 immune responses in pregnancy. Eur J Immunol 2007; 37: 1386-1396. [Medline] [CrossRef]

37. Wegmann TG, Lin H, Guilbert L, Mosmann TR. Bidirectional cytokine interactions in the maternal-fetal relationship: is successful pregnancy a TH2 phenomenon? Immunol Today 1993; 14: 353-356. [Medline] [CrossRef]

38. Raghupathy R. Th1-type immunity is incompatible with successful pregnancy. Immunol Today 1997; 18: 478-482. [Medline] [CrossRef]

39. Baratelli F, Lin Y, Zhu L, Yang SC, Heuzé-Vourch N, Zeng G, Reckamp K, Dohadwala M, Sharma S, Dubinett SM. Prostaglandin E2 induces FOXP3 gene expression and $\mathrm{T}$ regulatory cell function in human CD4+ T cells. J Immunol 2005; 175: 1483-1490.
[Medline] [CrossRef]

40. Bettelli E, Carrier Y, Gao W, Korn T, Strom TB, Oukka M, Weiner HL, Kuchroo VK. Reciprocal developmental pathways for the generation of pathogenic effector TH17 and regulatory T cells. Nature 2006; 441: 235-238. [Medline] [CrossRef]

41. Veldhoen M, Hocking RJ, Atkins CJ, Locksley RM, Stockinger B. TGFbeta in the context of an inflammatory cytokine milieu supports de novo differentiation of IL17-producing T cells. Immunity 2006; 24: 179-189. [Medline] [CrossRef]

42. Fujiwara H, Araki Y, Toshimori K. Is the zona pellucida an intrinsic source of signals activating maternal recognition of the developing mammalian embryo? J Reprod Immunol 2009; 81: 1-8. [Medline] [CrossRef]

43. Fujiwara H, Araki Y, Imakawa K, Saito S, Daikoku T, Shigeta M, Kanzaki H, Mori T. Dual positive regulation of embryo implantation by endocrine and immune systemsstep-by-step maternal recognition of the developing embryo. Am J Reprod Immunol 2016; 75: 281-289. [Medline] [CrossRef] 